\title{
Alergia alimentar: sistema imunológico e principais alimentos envolvidos
}

\author{
Food allergy: \\ system immunologic and main food involved
}

\author{
Ana Carolina da Silva Pereira ${ }^{1}$; Suelane Medeiros Moura²; \\ Patrícia Beltrão Lessa Constant ${ }^{3}$
}

\begin{abstract}
Resumo
A alergia alimentar pode ser definida como uma reação adversa a um antígeno alimentar mediada por mecanismos fundamentalmente imunológicos. É um problema nutricional que apresentou um crescimento nas ultimas décadas, provavelmente devido à maior exposição da população a um número maior de alérgenos alimentares disponíveis. Ele vem se tornando um problema de saúde em todo o mundo e está associado a um impacto negativo significativo na qualidade de vida. Os alimentos mais citados como causadores de alergias alimentares são: leite, ovos, amendoim, castanhas, camarão, peixe e soja, e os principais alérgenos alimentares identificados são de natureza protéica. É importante que haja investimento em pesquisas no sentido de reduzir os danos causados por alimentos que contém alérgenos. Estudos com a biotecnologia podem apresentar-se como uma alternativa eficiente e segura. Esta pesquisa tem como objetivo apresentar uma revisão atualizada das alergias alimentares, com foco principal no seu mecanismo de atuação no organismo.Também se discutem os principais alimentos envolvidos e as alternativas que vem sendo apresentadas para minimizar este problema.
\end{abstract}

Palavras-chave: Alergia. Alimentos. Reações adversas. Sistema imune.

\begin{abstract}
Food allergy can be defined as an adverse reaction to a food antigen mediated by fundamentally immunological mechanisms. It is a nutritional problem that has shown an increase in the last decades probably due to the population's exposure to a higher number of available food allergens. It has become a health problem worldwide being associated to a significant negative impact on life quality. The foods most cited as those which cause food allergy are: milk, eggs, peanuts, nuts, shrimps, fish and soy bean. The main food allergens are protein-nature ones. There must be investment in research in order to reduce the damage caused by foods containing allergens. Biotechnology studies can be considered an efficient and safe alternative. The purpose of this research is to present an updated review on food allergies focusing on its action mechanism in the body, main food involved and alternatives that have been used to minimize this problem.
\end{abstract}

Keywords: Allergy. Food. Adverse reactions. Immune system.

1 Engenheira de Alimentos Cursando Mestrado em Ciências e Tecnologia de Alimentos. E-mail: pblconstant@yahoo.com.br.

2 Engenheira de Alimentos Cursando Mestrado em Ciências e Tecnologia de Alimentos.

3 Professora Doutora da Universidade Federal do Ceará-UFC. 


\section{Introdução}

Os efeitos adversos que certos alimentos podem causar quando consumidos por alguns indivíduos, são conhecidos e relatados desde séculos a Antigüidade (CARVALHO JUNIOR, 2001). Equivocadamente tem se considerado alergias e as intolerâncias alimentares como sinônimos, e grande parte desses efeitos adversos são responsabilizados por promoverem processos alérgicos (ANGELIS, 2006).

A palavra alergia é proveniente do grego allan (outro) e ergon (trabalho). (FERNANDES, 2005). As reações alérgicas envolvem mecanismos imunológicos que podem ou não ser mediados pela IgE (Imunoglobulina E), que normalmente se encontra associada a alergias alimentares e reações de hipersensibilidade, tendo como característica a rápida liberação de mediadores como a histamina (CONSTANT, 2008; PORTERO; RODRIGUES, 2001; CABALLER, 2001; OJEDA CASAS, 2001). Já a termo intolerância alimentar refere-se a qualquer resposta anormal a um alimento ou aditivo, sem envolvimento de mecanismos imunes (LUIZ; SPERIDIÃO; FAGUNDES NETO, 2007).

As alergias são caracterizadas por um aumento na capacidade de os linfócitos B sintetizarem a imunoglobulina do isotipo $\operatorname{IgE}$ contra antígenos que acessam o organismo via inalação, ingestão ou penetração pela pele (MOREIRA, 2006). Tem sido observado um aumento de problemas alérgicos promovidos por alimentos em crianças e jovens nas últimas décadas (LARRAMENDI, 2003), o que tem contribuído negativamente para a qualidade de vida da população tornar-se um problema de saúde em todo mundo (FERREIRA; SEIDMAN, 2005; LOPES et al., 2006).

A alergia alimentar afeta $2,5 \%$ da população adulta. Entre 100 e 125 pessoas morrem por ano nos EUA por causa de uma reação alérgica alimentar (SANZ, 2001). Os riscos ao bem-estar aumentam à medida que os alimentos consumidos em uma população são cada vez mais processados e complexos, com rótulos inadequados (TAYLOR; HEFLE, 2006).

As AA são bem mais comuns no grupo pediátrico do que em adultos e possuem um impacto médico, financeiro e social considerável em crianças menores e suas famílias. Estudos sugerem que entre 5 e $25 \%$ dos adultos acreditam que eles ou seus filhos sejam atingidos (SAMPSON, 2005).

O tema é multiabrangente, e compreende um enorme leque de fatores que podem estar envolvidos, como uma resposta anormal a algum ingrediente protéico dos alimentos ingeridos, processos imunológicos, herança genética ou por anormalidades metabólicas (ANGELIS, 2006).

\section{Conceitos de Imunologia}

Anticorpos são proteínas produzidas em resposta a antígenos inativando-os. Admite-se que o ser humano fabrica cerca de dois milhões de moléculas de anticorpos. Os antígenos são substâncias estranhas ao corpo, proteínas, polipeptídios, ácidos nucléicos, de estruturas complexas, que contém um ou vários sítios antigênicos. Cada um provoca a formação de anticorpos diferentes (ANGELIS, 2006).

Os mastócitos e basófilos são células efetoras predominantes nas reações alérgicas. Durante a inflamação alérgica, os basófilos migram para os tecidos afetados, e contribuem com diversos mediadores. Eles são orientados na produção de citocinas Th2 (IL-4 e IL-13), estimulando a síntese de IgE e a atopia (LOPES et al., 2006).

O eosinófilo desempenha também um papel central na patogenia das doenças alérgicas é conhecido como potente célula efetora citotóxica. São glóbulos brancos que têm o poder de destruição de parasitas e tecidos, sendo, no entanto, susceptível de causar doença. A sua função é estimulada por mediadores lipídicos e citocinas libertadas por outras células (AMERICAN ACADEMY OF ALLERGY, ASTHMA AND IMMUNOLOGY - AAAAI, 2007; LOPES et al., 2006). 
Imunoglobulina A (IgA) é encontrada em secreções (lágrimas, saliva) e defende o corpo de microrganismos que podem invadir os sistemas respiratório e digestório. É quantitativamente o anticorpo mais importante do trato gastrointestinal e tem importante papel na redução da penetração mucosa do material antigênico ingerido (ANGELIS, 2006; BRICKS, 1994).

Imunoglobulina $\mathrm{M}$ (IgM) é um tipo de anticorpo temporáro, e forma-se quando um agressor novo ataca o organismo. Imunoglobulina G (IgG): é um anticorpo que assume o controle a partir da $\operatorname{IgM}$, a fim de formar uma memória duradoura, geralmente por toda a vida, e a Imunoglobulina E (IgE) é o anticorpo envolvido na alergia e na anafilaxia, além disso, protege o organismo contra parasitas intestinais (ANGELIS, 2006).

As células linfóides são encontradas nas amídalas, adenóides, timo, baço, placas de Peyer do intestino delgado, apêndice, gânglios linfáticos e medula óssea. Um tipo dessas células, chamadas linfócitos ou células B, que originam os plasmócitos, que fabricam os anticorpos (LOPES et al., 2006).

As células $\mathrm{T}$ constituem o elemento-chave da memória imunológica e, como tal, agentes fundamentais do sistema imunitário, são subdivididas em $\mathrm{T}$ auxiliares ou $\mathrm{T}$ supressoras (AAAAI, 2007; REIS, 1998). Ao atraírem células inflamatórias, limitam ciclos de expansão celular, induzem diferenciação/geração de propriedades funcionais. Elas também influenciam a regeneração e tolerância celular, e permitem o desenvolvimento de respostas imunes apropriadas, mantem a integridade e funcionalidade do organismo (LOPES et al., 2006).

\section{Sistema imune e alimentos}

O sistema imunológico é uma organização de células e moléculas com funções especializadas na defesa contra a infecção (DELVES; ROITT, 2000). Funciona como o mecanismo de defesa do corpo contra as incontáveis substâncias estranhas presentes no ar que respiramos, nos alimentos que ingerimos e nos objetos que tocamos. Dentro desse imenso grupo de substâncias estranhas, o termo "alérgeno" refere-se àquelas que resultam numa resposta imune alérgica (AAAAI, 2007).

Uma pessoa consome durante toda a sua vida cerca de 2-3 toneladas de alimentos diferentes. $\mathrm{O}$ sistema digestório os processa e os converte em material útil para o crescimento e manutenção das células do organismo (SANZ, 2001). Considerando a quantidade de alimentos que o sistema gastrointestinal de um indivíduo recebe durante a vida, não é surpreendente, sob certas circunstâncias, que este material estranho possa produzir uma reação adversa e/ou servir como veículo para agentes nocivos (MARTINS; GALEAZZI, 1996).

Em condições normais, a reação alérgica a alimentos é evitada, pois o trato gastrointestinal e o sistema imunológico fornecem uma barreira que impede a absorção da maioria dos antígenos (MOREIRA, 2006). Os alérgenos alimentares estáveis, resistem a temperatura, $\mathrm{pH}$, e a digestão enzimática e, por meio da sua ingestão, são capazes de induzir sensibilizações mediadas por IgE em indivíduos geneticamente predispostos. Já em sucessivas exposições por via digestiva produziram sintomas freqüentemente sistêmicos (FERNÁNDEZ-RIVAS, 2003).

O desenvolvimento do sistema imune local e sistêmico com o estimulo da microflora matura o sistema imune e impede a estruturação de resposta alérgica (BRANDT; SAMPAIO; MIUKI, 2006). A Imunidade pode ser definida como o conjunto concatenado de mecanismos e respostas utilizados pelo corpo para defendê-lo contra substâncias estranhas, microorganismos, toxinas e células não compatíveis (BERTOLA, 2001).

Osistemaimunedamucosadotratogastrointestinal exibe características peculiares, quando comparado à imunidade sistêmica. Recebendo uma carga antigênica maciça diariamente, via alimento, a 
vigilância imunológica precisa ser maior tanto do ponto de vista quantitativo quanto qualitativo (SOARES et al., 2001).

A mucosa gastrointestinal constitui uma porta de entrada aos antígenos alimentares e às bactérias não patogênicas da microflora, que representam uma forte fonte de perturbação da atividade imunológica no organismo. É também na mucosa que se localiza o maior número de macrófagos, polimorfonucleares, células dendrídicas, linfócitos $\mathrm{T}$ e linfócitos $\mathrm{B}$, secretores de imunoglobulinas (PEDRUZZI, 2002). As células $\mathrm{T}$ e $\mathrm{B}$ reconhecem os antígenos, mas não são capazes de distinguir entre os que são ou não perigosos. A chave dessa interpretação esta na sua interação com o sistema imune intestinal, concretamente nas placas de Peyer (SANZ, 2001).

No trato digestivo, os antígenos podem ser capturados por aglomerados de folículos linfóides situados na parede do intestino delgado, denominados de placas de Peyer, e neles se inicia a resposta imunitária das mucosas, com a produção da imunoglobulina IgA secretora (SIgA). A SIgA age como a primeira linha de defesa, servindo como interface entre os meios externo e interno (RAMALDES, 2003).

Em um indivíduo adulto cerca de $80 \%$ das células produtoras de anticorpos encontram-se associadas à mucosa do intestino delgado (BARTOLO, 2001).

Observa-se a produção de anticorpos IgG frente às proteínas de diferentes alimentos na maioria das pessoas sem que haja a indução de uma sintomatologia clinica. A maiorias das crianças, produzem pequenas quantidades de anticorpos específicos IgE frente a diferentes alimentos durante o primeiro ano de vida. Estes anticorpos desaparecem com o tempo. Em algumas crianças, relativamente poucas, os anticorpos específicos $\operatorname{IgE}$ permanecem e inclusive aumentam consideravelmente, e provocam sintomatologia alérgica gastrointestinal, dermatológica ou respiratória. Serão crianças alérgicas (LORENTE et al., 2001).
A apresentação clínica é muito variável, com sintomas que podem surgir na pele, no sistema gastrintestinal e respiratório. As reações podem ser leves, com simples coceira nos lábios, até reações graves que podem comprometer vários órgãos (ASSOCIAÇÃO BRASILEIRA DE ALERGIA E IMUNOPATOLOGIA - ASBAI, 2007).

É difícil classificar todos os tipos de reações imunológicas, relacionadas a prováveis alimentos. O único mecanismo claramente identificado implica as reações de hipersensibilidade imediata mediadas por anticorpos IgE com ativação de mastócitos (MARTİN ESTEBAN; POLANCO ALLUÈ, 2001). A produção de Imunoglobulina $\mathrm{E}$ ( $\mathrm{IgE}$ ) para um alimento específico geralmente ocorre em minutos após a ingestão do alimento(MARTINS, 2006).

Não se sabe perfeitamente por que algumas substâncias são alergênicas e outras não, nem por que nem todos os indivíduos desenvolvem uma reação alérgica após exporem-se aos alérgenos (AAAAI, 2007). A predisposição genética, a potência antigênica de alguns alimentos e alterações a nível do intestino parecem ter importante papel. Estudos indicam que de 50 a $70 \%$ dos pacientes com Alergia Alimentar possuem história familiar de alergia. Caso o pai e a mãe apresentam alergia, a probabilidade de terem filhos alérgicos é de $75 \%$ (ASBAI, 2007).

\section{Alimentos associados}

Para que a reação alérgica a um alimento ocorra, proteínas ou outros antígenos devem ser absorvidos pelo trato gastrointestinal, interagir com o sistema imunológico e produzir uma resposta (MOREIRA, 2006). Os alérgenos alimentares mais comuns responsáveis por até $90 \%$ de todas as reações alérgicas são as proteínas do leite de vaca, ovo, amendoim, trigo, soja, peixe, frutos do mar e nozes. (AAAAI, 2007; LOPES et al., 2006). Frutas cruas e vegetais são responsáveis pela Síndrome alérgica oral, que afeta aproximadamente $50 \%$ dos adultos 
com rinite causada por pólen. Dietas modernas que incluem alimentos exóticos e uma grande variedade de frutas e vegetais tem causado aumento de reações alérgicas a certas frutas, como kiwi e papaia, e a grãos, como gergelim, mostarda e canola (NOWAKWEGRZYN; SAMPSON, 2006).

Os alimentos podem provocar reações cruzadas, ou seja, alimentos diferentes podem induzir respostas alérgicas semelhantes no mesmo individuo. $\mathrm{O}$ paciente alérgico ao camarão pode não tolerar outros crustáceos. Da mesma forma, pacientes alérgicos ao amendoim podem também apresentar reação ao ingerir a soja, ervilha ou outros feijões (ASBAI, 2007).

\section{Leite}

Dentro do caótico estudo das alergias alimentares, a alergia ao leite de vaca é o modelo de estudo, pois apresenta a maior incidência e uma sintomatologia bastante variável. Seu estudo é prejudicado porque, na prática clínica, muitas vezes, os pesquisadores dividem-se em incrédulos, que subestimam sintomas, ou aqueles que os hiperestimam, levando crianças ao uso de dietas e privações desnecessárias, com graves conseqüências nutricionais e psicológicas. O desenvolvimento da alergia ao leite de vaca seguiu em paralelo com o desenvolvimento das civilizações. As primeiras descrições da alergia ao leite de vaca datam das eras bíblicas (CARVALHO JUNIOR, 2001).

O leite de vaca é uma mistura de mais de 20 componentes. Das proteínas implicadas nas reações imunológicas, os principais alérgenos encontrados neste alimento são a caseína, $\alpha$-lactoalbúmina e a ß-lactoglobulina (CASTELLO et al., 2004). A alergia ao leite de vaca é uma doença quase exclusiva dos lactentes e da infância, raramente é descrita na adolescência. $\mathrm{O}$ uso abusivo do leite de vaca como substituto do leite humano levou a um aumento da incidência dessa doença, esta incidência está situada entre 1,9 e 7,5\%. É freqüentemente descrita nos primeiros dois a três meses de idade e quase sempre desaparece após o quarto ano de vida. Estudos mostram que, na mesma família, a alergia ao leite de vaca pode apresentar manifestações clínicas diferentes e que as crianças com esse tipo de alergia podem desenvolver outros processos alérgicos, como eczema e asma (CARVALHO JUNIOR, 2001).

O ponto principal do tratamento da Alergia ao Leite de Vaca é a exclusão do leite de vaca e seus derivados, o que implica na capacidade de identificação das diferentes proteínas do leite, muitas vezes descritas por meio de termos pouco conhecidos para o consumidor. Assim, devese enfocar a necessidade da leitura atenta dos rótulos dos produtos industrializados, devendo ser rastreados nestes produtos antes do consumo termos como o: aseína, caseinatos, hidrolisados (de caseína, de proteínas do leite e do soro), lactoalbumina, $\beta$-lactoglobulina, soro de leite, creme de leite (ASBIA, 2007).

As indústrias de alimentos geralmente divulgam uma lista de seus produtos isentos de leite de vaca. Pode-se solicitar esta relação através do contato com o SAC (Sistema de Atendimento ao Consumidor) das respectivas empresas. Pelo fato de existirem freqüentes modificações dos ingredientes destes produtos, é necessário que a lista esteja atualizada e conferida antes do consumo (ASBIA, 2007).

Algumas publicações chamaram a atenção para os eventuais efeitos adversos das dietas de exclusão de leite nas crianças. Foram descrito casos de hipocrescimento nas crianças que seguem uma dieta sem produtos lácteos. Foram descritos também suprimento calórico insuficiente, baixo suprimento de cálcio e sinais bioquímicos de nutrição inadequada em crianças com menos de 4 anos (VILLARES et al., 2006).

\section{Ovo}

A ocorrência de alergia ao ovo é mais freqüente nos primeiros anos de vida, geralmente devido às 
proteínas da clara (CASTELLO et al., 2004). A alergia ao ovo afeta $0,5 \%$ das crianças saudáveis, até $5 \%$ dos bebês atópicos e $50 \%$ das crianças com dermatite atópica podem apresentar alergia a esse alimento. Entre os principais alérgenos da clara do ovo já identificados, salientam-se a ovoalbumina (Gal d 1), o ovomucóide (Gal d 3) e a conalbumina (Gal d 2), que constituem 54\%, 11\% e 12\% da proteína total da clara, respectivamente (BATISTA, et al., 2007).

A alergia ao ovo pode ser classificada como imediata ou tardia. A primeira ocorre em até quatro horas após a ingestão do ovo, e a segunda ocorre em período superior a este espaço de tempo. As reações imediatas envolvem mecanismo IgE mediados, sendo as mais comuns: anafilaxia, hipotensão, urticária, choque, broncoespasmo, laringoespasmo ou síndrome da alergia oral (BATISTA, et al., 2007).

A ovoalbumina pode estimular uma reação de hipersensibilidade do tipo IgE mediada a alimentos, levando à liberação de mediadores de células mastocitárias (histamina), que atuam sobre a pele, nariz, pulmões e trato gastrointestinal. As alterações decorrentes do efeito da histamina envolvem o aumento da permeabilidade capilar, a vasodilatação, a contração de músculo liso e a secreção de muco (BATISTA, et al., 2007).

\section{Mariscos}

As reações de hipersensibilidade a ingestão de mariscos constituem uma das alergias alimentares mais freqüentes nos adultos. A maioria são alergias múltiplas a mariscos, tais comoalagosta, caranguejoe camarão, os indivíduos podem desenvolver urticária, angiodemas, asma e quadros de anafilaxia. Foi demonstrada a presença de antígenos termoestáveis e termolábeis no camarão. E em estudos recentes, foi identificada como o alérgeno do camarão uma proteína muscular a tropomiosina (HERRERO et al., 2001).

\section{Aditivos}

Devido ao desenvolvimento tecnológico e as mudanças nos hábitos alimentares, tem aumentando a exposição da população a uma grande variedade de aditivos e contaminantes, principalmente nos alimentos processados, e isso vem criando um microambiente no intestino que favorece $o$ desenvolvimento das reações adversas (TOCHE, 2004).

Os aditivos em alimentos podem servir para muitos propósitos, desde o de realçar a cor e o sabor dos alimentos até o de atuar como complemento nutricional e como agente antimicrobiano. A maioria dos aditivos é ingerida em pequenas quantidades e os efeitos adversos decorrentes da sua ingestão podem variar de letargia a crises de asma grave. $\mathrm{O}$ diagnóstico preciso de reação alérgica a aditivos só pode ser feito através de procedimentos de provocação apropriados(OLIVEIRA; GRAUDENZ, 2003).

O Sistema Internacional de Numeração (INS, International Numbering System) de Aditivos Alimentares foi elaborado pelo Comitê do Codex Alimentarius da Organização de Alimentos e Agricultura da Organização Mundial de Saúde (FAO/OMS) sobre Aditivos Alimentares e Contaminantes de Alimentos, para estabelecer um sistema numérico internacional de identificação dos aditivos alimentares nas listas de ingredientes como alternativas à declaração do nome específico do aditivo. Embora não se conheça o potencial alergênico de todas as substâncias citadas nessa lista, parte delas já foi relacionada a reações alergênicas como urticária e/ou angioedema. É o caso de alergias relacionadas aos parabenos, à lanolina, ao metabissulfito de sódio e aos sulfitos (OLIVEIRA; GRAUDENZ, 2003).

Os dados de alergia a aditivos alimentares no Brasil são escassos e carecem de metodologia rigorosa. No entanto, apesar de não ser conhecida a prevalência de reações alérgicas a aditivos alimentares no Brasil, estima-se que sua prevalência 
em países desenvolvidos - comprovada por testes de provocação, varie de 0,01 a $0,23 \%$. Por último, é interessante ressaltar que o INS não supõe uma aprovação toxicológica da substância pelo Codex (OLIVEIRA; GRAUDENZ, 2003).

As reações adversas aos conservantes, corantes e aditivos alimentares são raras, mas não devem ser menosprezadas. O corante artificial tartrazina, sulfitos e glutamato monossódico são relatados como causadores de reações. A tartrazina pode ser encontrada nos sucos artificiais, gelatinas e balas coloridas, enquanto o glutamato monossódico pode estar presente nos alimentos salgados como temperos (caldos de carne ou galinha). Os sulfitos são usados como preservativos em alimentos (frutas desidratadas, vinhos, sucos industrializados) e medicamentos tem sido relacionados a crises de asma em indivíduos sensíveis. O metabissulfito de sódio causa reações mais freqüentes (urticária e exacerbação da asma). O citrato de sódio, usado como antioxidante, pode causar reações alérgicas, além da queda da pressão arterial, vermelhidão da pele e dor de cabeça; porém, mais raramente que os sulfitos (ASBIA, 2007).

\section{Alimentos transgênicos e as alergias}

$\mathrm{O}$ número de pessoas que contraem alergia alimentar está aumentando a cada ano, além do crescente hábito da população de realizar suas refeições fora de casa. Isso significa que as reações alérgicas inesperadas tendem a ser um problema em expansão. Logo, é importante que haja investimento em pesquisas no sentido de reduzir os danos causados por alimentos que contém alérgenos. E a biotecnologia pode contribuir para isso de maneira eficiente e segura (WILSON, 2007). Substâncias que causam alergias podem ser removidas em alimentos transgênicos. Já se produziu uma variedade de arroz com baixíssima capacidade de causar alergia (BARTOLOMÉ, 2001). Um alimento muito alergênico, o trigo, também está sendo modificado e as pesquisas são promissoras. Já no caso do amendoim, que possui proteínas alergênicas em grandes quantidades, a produção de variedades pouco alergênicas levará ainda algum tempo (BRUNORO; AZEREDO, 2007).

A Organização Mundial da Saúde reconhece que a engenharia genética oferece a oportunidade de diminuir - ou mesmo de eliminar - nos alimentos os compostos que provocam alergias. Tanto é assim que muitos pesquisadores têm se dedicado a suprimir naturalmente os alergênicos presentes no trigo, no leite e até no amendoim. Atualmente, também já se encontra em desenvolvimento uma variedade de soja transgênica, desenvolvida para não provocar reações alérgicas (WATANABE; MARIN, 2007).

O relatório da União de Academias de Ciência e Humanidades da Alemanha, conduzido sob ponto de vista estritamente científico e com base em estudos liderados por pesquisadores idôneos, apresentou evidências de que alimentos derivados de plantas transgênicas são equivalentes ou mesmo superiores as suas contrapartes convencionais, no que se refere a questões de saúde. Foram levados em conta o potencial carcinogênico, toxigênico e alergênico desses alimentos, bem como possíveis efeitos indesejáveis resultantes da ingestão de DNA transgênico (AZEREDO, 2007). A existência de riscos associados aos organismos geneticamente modificados (OGM) tem sido questionada há mais de vinte anos, muito antes de qualquer produto transgênico chegar ao mercado, e isso gera grandes discussões que envolveram governos, agricultores, comerciantes, associações de defesa dos animais, entre outros (CAVALLI, 2001).

Os alimentos transgênicos são submetidos a testes rigorosos antes de sua liberação, e usam animais de laboratório, o que não ocorre com alimentos elaborados com plantas obtidas por métodos convencionais $\mathrm{O}$ receio de que o consumo de alimentos derivados de plantas GM resulte em grande risco de manifestações alérgicas é um dos argumentos bastante explorados por ativistas antibiotecnologia. Entretanto, como os alimentos 
transgênicos são obrigatoriamente testados para avaliar seu potencial alergênico, por meio de protocolos aprovados por organismos internacionais, sua segurança é muito maior do que os alimentos convencionais (AZEREDO, 2007; BORÉM; COSTA, 2002).

Uma árvore de decisões para a avaliação do potencial de alergenicidade de novas proteínas em alimentos geneticamente modificados foi desenvolvida, em 1996, pelo Conselho Internacional de Biotecnologia de Alimentos e pelo Instituto de Alergia e Imunologia do ILSI (International Life Sciences Institute) (WATANABE; NUTTI, 2002). Esse processo de decisão foi posteriormente revisado, em 2001, pelos peritos que participaram da consulta conjunta da FAO/WHO sobre alimentos derivados da biotecnologia (WORLD HEALTH ORGANIZATION - WHO, 2001). Qualquer resultado positivo define o produto como sendo alergênico, e leva à interrupção do desenvolvimento do produto. Um resultado negativo implica a realização de testes in vitro adicionais, realizados com soro de pacientes hipersensibilizados a certos grupos de alérgenos relacionados à fonte original do gene; implica também o teste de resistência da proteína expressa à digestão pela pepsina ("digestive fate") e a determinação da imunogenicidade em modelos animais (MUNIZ et al., 2003).

Testes in vivo com humanos podem ser considerados em alguns casos, porém não são obrigatórios. No caso da nova proteína proceder de uma fonte não reconhecida como alergênica, a árvore de decisões busca a similaridade da seqüência com alérgenos conhecidos e subseqüente teste in vitro com soro de pacientes hipersensibilizados àqueles grupos de alérgenos relacionados à fonte original do gene. A proteína é considerada alergênica quando for verificada homologia da seqüência e o resultado do teste com soro for positivo. Quando os resultados forem negativos, testes adicionais de resistência da nova proteína à digestão pela pepsina e testes de imunogenicidade em modelos animais podem indicar a alta ou baixa probabilidade do potencial alergênico da nova proteína (WATANABE; MARIN, 2007; WHO, 2001).

Até o momento, não se tem conhecimento de nenhum produto agrícola ou alimento geneticamente modificado aprovado que tenha causado alergias. A tecnologia de modificação genética oferece a oportunidade de reduzir ou eliminar alergênicos protéicos que ocorrem naturalmente em alimentos específicos (WHO, 2001). Assim, a biotecnologia tem trabalhado para reduzir problemas com alergias alimentares e não para agraválos (WATANABE; NUTTI, 2002).

\section{Alergia alimentar na infância}

Reações adversas a alimentos são mais comuns em crianças de baixa idade, e isso pode ser relacionado, em parte, com os hábitos de alimentação da população avaliada (BRICKS, 1994). Em um estudo prospectivo com 480 recém-nascidos nos Estados Unidos, reações adversas foram relatadas pelos pais em $28 \%$ dos lactentes, entretanto, esses relatos só foram confirmados por desafio oral em apenas um terço dos casos suspeitos, ou seja, $8 \%$ do total do grupo avaliado 5. A alergia alimentar afeta de 6 a $8 \%$ dos lactentes jovens e 1,5 a $2 \%$ da população adulta (LUIZ; SPERIDIÃO; FAGUNDES NETO, 2007).

A incidência da alergia alimentar dá-se principalmente dentro dos primeiros seis meses de vida, e afeta especialmente lactentes que receberam aleitamento natural por um período de tempo muito curto ou então, aqueles que se viram totalmente privados da prática do aleitamento natural (LUIZ; SPERIDIÃO; FAGUNDES NETO, 2007).

O leite, seja o materno ou em fórmula infantil, constitui o primeiro alimento em contacto com o lactante, sendo por isso a sua primeira fonte de antígenos alimentares. Portanto, não é de estranhar que durante o primeiro ano de vida seja o alimento responsável pelo maior número de reações adversas (VILLARES et al., 2006). 
É possível prevenir ou retardar a aparição de alergias em crianças mediante intervenções dietéticas que se iniciam desde a gravidez. Em mães com antecedentes alérgicos, recomenda-se evitar durante a gravidez os alimentos alergênicos tais como, leite, ovo, pescados, mariscos, amendoim e soja, e substituí-los por outros que não comprometam seu estado nutricional, complementando com cálcio quando necessário. A mãe deve continuar evitando os alimentos durante o aleitamento materno exclusivo e mantê-lo por no mínimo seis meses, já que alérgenos alimentares podem ser transmitidos através do leite materno (BRICKS, 1994; LUIZ; SPERIDIÃO; FAGUNDES NETO, 2007).

A introdução de alimentos sólidos com potencial alergênico deve ser adiada em crianças com antecedentes familiares de alergia. Recomenda-se que a introdução desses alimentos aconteça após o primeiro ano de idade para alimentos como, ovo, pescados e soja. Por volta dos três anos de idade, pode-se introduzir o amendoim. Apesar de todas as dificuldades quanto ao diagnóstico correto da alergia alimentar, sua importância é inquestionável na faixa etária pediátrica, sendo necessária uma abordagem ampla, na qual envolve atendimento multidisciplinar e a conscientização da família quanto à importância das orientações a serem seguidas, objetivando o controle dos sintomas (LUIZ; SPERIDIÃO; FAGUNDES NETO, 2007).

\section{Diagnóstico de alergia alimentar}

O diagnóstico correto da alergia alimentar é fundamental para o tratamento adequado e para que não se instituam dietas desnecessárias. O diagnóstico depende de história clínica minuciosa associada aos dados de exame físico que podem ser complementados por testes alérgicos. Na história clínica, é fundamental que o paciente ou seus pais, no caso das crianças, auxilie e forneça pormenores acerca dos alimentos ingeridos rotineiramente ou eventualmente. Em algumas situações, é possível correlacionar o surgimento dos sintomas com a ingestão de determinado alimento. Em outras ocasiões, o quadro não é tão evidente, necessitando de história mais detalhada. Isso ocorre principalmente quando as reações ocorrem horas após a ingestão do alérgeno (FERNANDES; PRATES, 2007; ASBAI, 2007).

O teste alérgico é um método de diagnóstico seguro e geralmente indolor. Deve ser realizado pelo médico especialista que, após a história clínica e o exame físico, determinará quais substâncias podem ter importância no quadro clínico e, portanto, deverão ser avaliadas. O desconforto pode ocorrer pelo prurido (coceira) localizado à área do teste, no caso da reação positiva. Na maioria das vezes é realizado no antebraço após higiene local com algodão e álcool. O resultado é obtido em 15 a 20 minutos e a reação positiva consiste na formação de uma pápula vermelha, semelhante à uma picada de mosquito. Esta reação indica presença de IgE específica ao alimento testado. Algumas vezes torna-se necessário realizar o teste com o próprio alimento in natura (ASBAI, 2007).

As provas de provocação alimentar assumem importância fundamental, uma vez que a sensibilidade clínica do doente, assim como o limiar de reação, não podem ser previstos com base na sensibilidade demonstrada quer por testes cutâneos por picada ou epicutâneos, quer in vitro, por meio do doseamento de IgE específicas (LOPES et al., 2006).

\section{Tratamento de alergias alimentares}

Até o momento, não existe um medicamento específico para prevenir a Alergia Alimentar. Uma vez diagnosticada, são utilizados medicamentos específicos para o tratamento dos sintomas (crise) sendo de extrema importância fornecer orientações ao paciente e familiares para que se evite novos contatos com o alimento desencadeante. As orientações devem ser fornecidas por escrito, visando à substituição do alimento excluído e evitando-se deficiências nutricionais até quadros de 
desnutrição importante principalmente nas crianças. O paciente deve estar sempre atento, e verificar o rótulo dos alimentos industrializados buscando identificar nomes relacionados ao alimento que lhe desencadeou a alergia (ASBAI, 2007).

A exclusão de um determinado alimento não é tarefa fácil e a exposição acidental ocorre com certa freqüência. Os indivíduos com Alergia Alimentar grave (reação anafilática) devem portar braceletes ou cartões que os identifiquem, para que cuidados médicos sejam imediatamente tomados. As reações leves desaparecem espontaneamente ou respondem aos anti-histamínicos (antialérgicos). Pacientes com história de reações graves devem ser orientados a portar medicamentos específicos (adrenalina), mas torna-se obrigatório uma avaliação em serviço de emergência para tratamento adequado e observação, pois, em alguns casos, pode ocorrer uma segunda reação, tardia, horas após (ASBAI, 2007).

Em alguns casos, principalmente nas crianças, a exclusão rigorosa do alimento parece promover a diminuição da alergia. $\mathrm{O}$ alimento deve permanecer suspenso por aproximadamente 6 meses. Após este período o médico especialista poderá recomendar uma reintrodução do alimento e observar os sintomas. Se o indivíduo permanecer assintomático e conseguir ingerir o alimento, o mesmo pode ser liberado. Caso ocorra qualquer sintoma, a dieta de eliminação deve ser mantida. A presença de reação alérgica grave, como a anafilaxia ao amendoim, contra-indica esta reintrodução. Nos pacientes altamente sensibilizados, a presença de quantidades mínimas do alimento pode desencadear reação de extrema gravidade (ASBAI, 2007).

\section{Métodos de prevenção da alergia alimentar}

O estímulo ao aleitamento materno no primeiro ano de vida é fundamental assim como a introdução tardia dos alimentos sólidos potencialmente provocadores de alergia. As recomendações da idade de introdução de alimentos específicos, com maior potencial alergénico, como o ovo, o peixe e os frutos secos, variam um pouco consoante os autores, respeitando diferentes populações. Segundo a Sociedade Americana de Pediatria (AAP), recomenda-se a introdução dos alimentos sólidos após o $6^{\circ}$ mês, o leite de vaca após 1 ano de idade, ovos aos 2 anos e amendoim, nozes e peixe, somente após o $3^{\circ}$ ano de vida (ASBAI, 2007; CARRAPATOSO; SARINHO, 2007).

A dieta materna durante a amamentação parece ter algum benefício na prevenção da alergia às proteínas do leite de vaca e no eczema atópico. Durante o aleitamento materno, a restrição de alguns alimentos alergizantes, como produtos lácteos, ovo, peixe, amendoim e soja, pode ser associada à redução da prevalência de eczema atópico dos 12 aos 18. No entanto, esta dieta alimentar só deve ser realizada sob supervisão médica e em mães com grande risco de ter filhos com alergia. A introdução precoce de alérgenos alimentares pode promover o desenvolvimento de alergia enquanto que a introdução numa fase mais tardia induz tolerância. Os alimentos sólidos antes dos quatro meses podem aumentar o risco de eczema atópico em crianças com predisposição genética, no entanto alguns estudos falharam ao tentar mostrar benefícios na introdução mais tardia destes alimentos (FERREIRA; COELHO; TRINDADE, 2007).

Alimentos processados, por conterem vários alérgenos, não devem ser introduzidos enquanto não se confirmar a tolerância a cada um dos ingredientes. Não existem, atualmente, estudos controlados que permitam demonstrar o papel preventivo da introdução de alimentos sólidos específicos em determinadasidades (CARRAPATOSO; SARINHO, 2007).

\section{Referências}

AMERICAN ACADEMY OF ALLERGY, ASTHMA AND IMMUNOLOGY - AAAAI. Tips to remember: food allergy. Disponível em: <http://www.aaaai.org/ patients/publicedmat/tips/foodallergy.stm $>$. Acesso em: 1 out. 2007. 
ANGELIS, R. C. Alergias alimentares: tentando entender por que existem pessoas sensíveis a determinados alimentos. São Paulo: Atheneu, 2006.

ASSOCIAÇÃO BRASILEIRA DE ALERGIA E IMUNOPATOLOGIA - ASBAI. Alergia alimentar. Disponível em: <http://www.sbai.org.br/publico8.htm>. Acesso em: 1 out. 2007.

AZEREDO, R. M. C. O. Alimentos transgênicos: segurança para a saúde. Disponível em: $<$ http://www.cib. org.br/artigo.php?inicio=15>. Acesso em: 10 nov. 2007.

BARTOLO, 2001.

BARTOLOMÉ, B. Alimentos transgénicos: por qué y cómo se desarrollan. Alergologia e Inmunologia Clinica, Madrid, v. 16, n. 2, p. 137-1532, 2001.

BATISTA, J. L.; PASTORINO, A. C.; GRUMACH, A. S.; JACOB, C. M. A. Reações adversas à vacina $M M R$ em pacientes alérgicos a ovo: revisão da literatura. Revisões e ensaios reviews and essays. Disponível em: $<$ http://www.pediatriasaopaulo.usp.br/upload/html/453/ body/09.htm>. Acesso em: 2 out. 2007.

BERTOLA, 2001.

BORÉM, A.; COSTA, N. M. B. Potencial nutricional e funcional dos alimentos geneticamente modificados. Nutrição Brasil, Rio de Janeiro, v. 1, n. 4, p. 230-233, nov./dez. 2002.

BRANDT, K. G.; SAMPAIO, M. M. S. C.; MIUKI, C. J. Importância da microflora intestinal. Revisões e Ensaios: Pediatria, São Paulo, v. 28, n. 2, p. 117-127, 2006.

BRICKS, L. F. Reações adversas aos alimentos na infância: intolerância e alergia alimentar: atualização. Pediatria, São Paulo, v. 16, n. 4, p. 176-185, 1994.

BRUNORO, N.; AZEREDO, R. O potencial dos alimentos GMs no combate a doenças. Disponível em: < $\mathrm{http} / / / \mathrm{www}$.cib.org.br/artigo.php?inicio=30>. Acesso em : 10 nov. 2007.

CABALLER, 2001.

CARRAPATOSO. I.; SARINHO, E. Será possível prevenir a alergia alimentar? Revista Portuguesa de Imunoalergologia, Lisboa, v. 15, n. 4, p. 291-299, 2007.

CARVALHO JUNIOR, F. F. Apresentação clínica da alergia ao leite de vaca com sintomatologia respiratória. Jornal de Pneumologia, São Paulo, v. 27, n. 1, jan./fev. 2001.

CASTEllo, M. A.; HEVIA, X.; GÓMEZ, I. M.; CASTRO, A. R.; RODRÍGUEZ, C. J. Algunas consideraciones sobre las reacciones adversas por alimentos. Revista Cubana de Medicina General Integral, Habana, v. 20, n. 5-6, p. 0-0, Sep./Dec. 2004.
CAVALLI, S. B. Segurança alimentar: a abordagem dos alimentos transgênicos. Revista Nutrição, Campinas, v. 14, Supl., p. 41-46, 2001.

CONSTANT, 2008.

DELVES, P. J.; ROITT, I. M. Advances in immunology: the immune system. The New England Journal of Medicine, Boston, v. 343, n. 1, p. 37-49, Jul. 2000.

FERNANDES, M. E. Alergia alimentar em cães. 2005. Dissertação. (Mestrado em Saúde Publica) - Faculdade de Saúde Pública, Universidade de São Paulo, São Paulo.

FERNANDES, N. P.; PRATES, S. Qual o papel do patch test no diagnóstico da alergia alimentar? Revista Portuguesa de Imunoalergologia, Lisboa, v. 15, n. 5, p. 377-385, 2007.

FERNÁNDEZ-RIVAS, M. Alergia a alimentos: patrones de respuesta clínica a los alergenos alimentarios. Alergologia e Inmunologia Clinica, Madrid, v. 18, n. 3, p. 119-120. 2003.

FERREIRA, C. T.; SEIDMAN, E. Alergia alimentar: atualização prática do ponto de vista gastroenterológico. Jornal de Pediatria, Rio de Janeiro, v. 83, n. 1, p. 7-20, 2007.

\section{FERREIRA; SEIDMAN, 2005.}

FERREIRA, M.; COELHO, R.; TRINDADE, J. C. Prevenção primária da doença alérgica. Acta Médica Portuguesa, Lisboa, v. 20, n. 3, p. 215-219, 2007.

HERRERO, M. D.; GÓMEZ, M.; OJEDA, P.; MONEO Y, I.; ALDAY, E. Hipersensibilidad a crustáceos y detección de IgE específica. Alergologia e Inmunologia Clinica, Madrid, v. 16, n. 1, p. 13-17. 2001.

\section{LARRAMENDI, 2003.}

LOPES, C. RAVASQUEIRA, A.; SILVA, I.; CAIADO, J.; DUARTE, F.; DIDENKO, I.; SALGADO, M.; SILVA, S. P.; FERRÃO, A.; PITÉ, H.; PATRÍCIO, L.; BORREGO, L. M. Allergy School Hannover 2006: Allergy, from diagnosis to treatment. Revista Portuguesa de Imunoalergologia, Lisboa, v. 14, n. 4, p. 355-364, 2006.

LORENTE, F.; LAFFOND, E.; DÁVILA, I.; MORENO, E. Mecanismos de tolerancia inmunológica. Prevención primaria de la alergia a alimentos. Alergologia e Inmunologia Clinica, Madrid, v. 16, n. 2, p. 62-75. 2001.

LUIZ, V. F. C.; SPERIDIÃO, P. G. L.; FAGUNDES NETO, U. Terapia nutricional nas intolerâncias e alergias alimentares. Electronic Journal of Pediatric Gastroenterology, Nutrition and Liver Diseases. 
Disponível em: <http://www.e-gastroped.com.br/jun05/ terapia_nutricional.htm>. Acesso em: 1 out. 2007.

MARTİN ESTEBAN, M.; POLANCO ALLUÈ, I. Enfermedades alérgicas inducidas por alimentos no exclusivamente mediadas por ige: gastroenteropatías inducidas por alimentos. Alergologia e Inmunologia Clinica, Madrid, v. 16, n. 2, p. 79-85, 2001.

MARTINS, M. T. S.; GALEAZZI, M. A. M. Alergia alimentar: considerações sobre o uso de proteínas modificadas enzimaticamente. Revista Cadernos de Debate, Campinas, v. 4, p. 1-24, 1996.

MARTINS, N. F. Predição de proteinas alergênicas. Brasília: Embrapa Recursos Genéticos e Biotecnologia, 2006. (Documentos, 205).

MOREIRA, L. F. Estudo dos componentes nutricionais e Imunológicos na perda de peso em Camundongos com alergia alimentar. 2006. Dissertação (Mestrado em Patologia Geral) - Universidade Federal de Minas Gerais, Belo Horizonte.

MUNIZ, C. R.; FREITAS, C. A. S.; CAMPÊLO, W. F.; MAIA, G. A.; BRASIL, I. M. Alimentos transgênicos: segurança, riscos alimentares e regulamentações. $B$. CEPPA, Curitiba, v. 21, n. 2, p. 209-222, jul./dez. 2003.

NOWAK-WEGRZYN, A; SAMPSON, H. A. Adverse reactions to food. Medical Clinics of North America, Philadelphia, v. 90, n 1, p. 77-95, jan. 2006.

OJEDA CASAS, 2001.

OLIVEIRA; GRAUDENZ, 2003.

PEDRUZZI, 2002.

PORTERO, K. C. C., RODRIGUES, E. M. Aspectos clínicos e imunológicos da alergia alimentar. Nutrição em Pauta, São Paulo, n. 50, p. 41-44, set/out. 2001.

RAMALDES, 2003.

RAMALDES, G. A.; PEREIRA, M. A.; CASTRO, P. T.; VIEIRA, L. M.; CARDOSO, V. N. Captura de lipossomas pelas placas de Peyer de camundongos após administração oral. Revista Brasileira de Ciências Farmacêuticas, São Paulo, v. 38, n. 2, abr./jun. 2002.
REIS, A. P. Imunoterapia em pediatria. Indicar ou não indicar e quando. Pediatria, São Paulo, v. 20, n. 2, p. 106-111, 1998.

\section{SAMPSON, 2005.}

SANZ, M. L. Inmunidad del tracto intestinal: procesamiento de antígenos. Alergologia e Inmunologia Clinica, Madrid, v. 16, n. 2, p. 58-62, 2001.

SOARES, R. L. S.; FIGUEIREDO, H. N.; DICK, M. F. S.; SILVA FILHO, N. F.; LIMA, L. F. Q.; SANTOS, J. M. A síndrome do intestino irritável associada à intolerância alimentar. Mundo \& Vida, Niterói, v. 2, n. 1/2, p. 20-32, 2001.

TAYLOR; HEFLE, 2006.

TOCHE, P. P. Alergia a alimentos y aditivos. Revista Médica Clínica las Condes, Santiago, v. 15, n. 3, p.9297, jul. 2004.

VILLARES, J. M. M.; OLIVEROS LEAL, L.; TORRES PERAL, R.; LUNA PAREDES, C.; MARTÍNEZGIMENO, A.; GARCÍA-HERNÁNDEZ, Y. G. Como crescem os lactentes alérgicos às proteínas de leite de vaca. Anales de Pediatría, Barcelona, v. 1, n. 2, p. 97100, 2006.

WATANABE, E.; MARIN, V. A. Biotecnologia pode reduzir a incidência de alergias alimentares. Disponível em $\quad:<$ http://www.cib.org.br/artigo.php?inicio=15>. Acesso em: 10 nov. 2007.

WATANABE, E.; NUTTI, M. R. Alimentos geneticamente modificados: avaliação de segurança e melhorias de qualidade em desenvolvimento. Revista Brasileira de Milho e Sorgo, Sete Lagoas, v. 1, n. 1, p. 1-14. 2002.

WORLD HEALTH ORGANIZATION - WHO. Evaluation of allergenicity of genetically modified foods. Report of a joint FAO/WHO expert consultation on allergenicity of foodsderived from biotechnology. 2001. Disponível em: $<\mathrm{ftp}: / / \mathrm{ftp}$.fao.org/es/esn/food/allergygm. pdf>. Acesso em: 11 nov. 2007.

WILSON, K. Biotech vs. Peanut Allergies. American Council on Science and Health. Disponível em: $<$ http:// www.acsh.org/factsfears /newsID.1007/news_detail. asp>. Acesso em: 7 nov. 2007. 